\title{
Computer-Implemented Articulatory Models for Speech Production: A Review
}

\author{
Bernd J. Kröger* \\ Department of Phoniatrics, Pedaudiology, and Communication Disorders, RWTH Aachen University, Aachen, Germany
}

Modeling speech production and speech articulation is still an evolving research topic. Some current core questions are: What is the underlying (neural) organization for controlling speech articulation? How to model speech articulators like lips and tongue and their movements in an efficient but also biologically realistic way? How to develop highquality articulatory-acoustic models leading to high-quality articulatory speech synthesis? Thus, on the one hand computer-modeling will help us to unfold underlying biological as well as acoustic-articulatory concepts of speech production and on the other hand further modeling efforts will help us to reach the goal of high-quality articulatory-acoustic speech synthesis based on more detailed knowledge on vocal tract acoustics and speech articulation. Currently, articulatory models are not able to reach the quality level of

OPEN ACCESS

Edited by:

Nadia Magnenat Thalmann, Université de Genève, Switzerland

Reviewed by:

Christopher Carignan,

University College London, United Kingdom Xavier Hinaut,

Inria Bordeaux -Sud-Ouest Research Centre, France

*Correspondence: Bernd J. Kröger bernd.kroeger@mth-aachen.de

Specialty section: This article was submitted to Humanoid Robotics, a section of the journal Frontiers in Robotics and Al

Received: 17 October 2021 Accepted: 21 February 2022 Published: 08 March 2022

Citation:

Kröger BJ (2022) ComputerImplemented Articulatory Models for

Speech Production: A Review.

Front. Robot. Al 9:796739.

doi: 10.3389/frobt.2022.796739 corpus-based speech synthesis. Moreover, biomechanical and neuromuscular based approaches are complex and still not usable for sentence-level speech synthesis. This paper lists many computer-implemented articulatory models and provides criteria for dividing articulatory models in different categories. A recent major research question, i.e., how to control articulatory models in a neurobiologically adequate manner is discussed in detail. It can be concluded that there is a strong need to further developing articulatory-acoustic models in order to test quantitative neurobiologically based control concepts for speech articulation as well as to uncover the remaining details in human articulatory and acoustic signal generation. Furthermore, these efforts may help us to approach the goal of establishing high-quality articulatory-acoustic as well as neurobiologically grounded speech synthesis.

Keywords: articulatory model, speech production, biomechanical model, vocal tract, speech acoustics

\section{INTRODUCTION}

An articulatory model is a quantitative computer-implemented emulation or mechanical replication of the human speech organs. It can be extended towards an articulatory-acoustic model if in addition an acoustic speech signal is produced based on the geometrical information provided by the articulatory model. Thus, the term articulatory model will include articulatory-acoustic models in this paper. The speech organs modeled in these approaches can be divided in sub-laryngeal, laryngeal, and supra-laryngeal organs. The sub-laryngeal system comprising lungs and trachea provides subglottal pressure and sufficient airflow for speaking, the laryngeal system provides the phonatory signal (primary source signal), and the supra-laryngeal system comprising pharyngeal, oral, and nasal cavities and comprising the articulators for modifying the shape of the pharyngeal and 


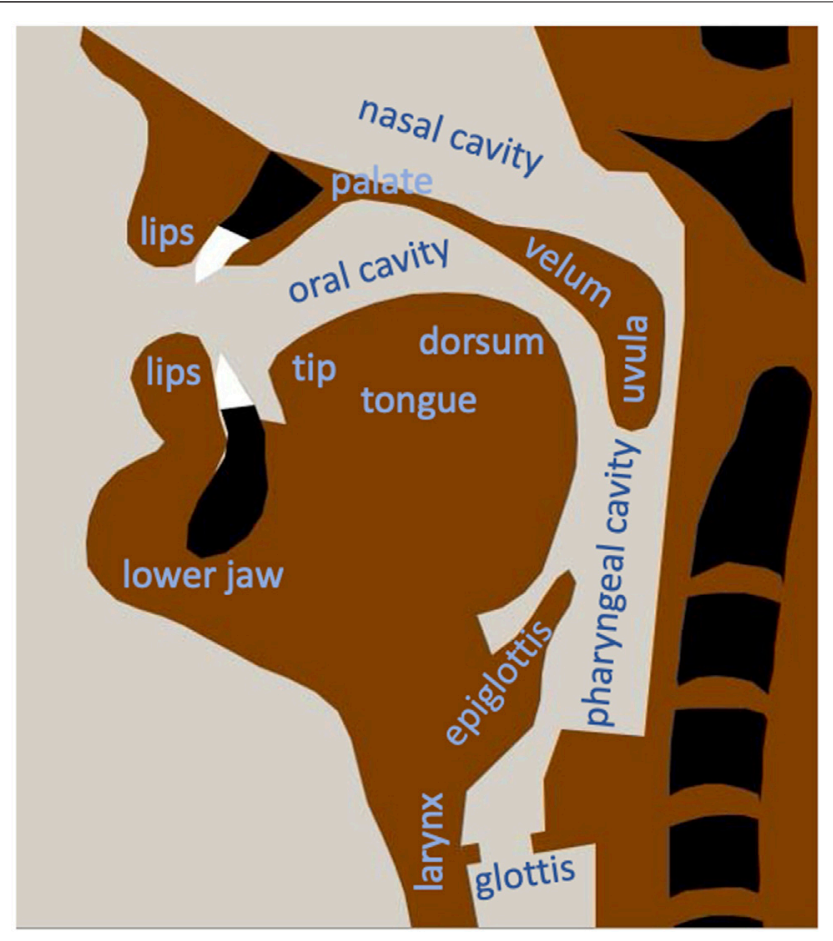

FIGURE 1 | Midsagittal view generated using the two-dimensional articulatory model of Kröger et al. (2014).

oral cavity, i.e., lower jaw, lips, and tongue, modify the phonatory signal and generates secondary source signals (frication noise) in case of the occurrence of appropriate constrictions. It is the main task of an articulatory model to produce natural articulatory speech movements based on articulatory control commands and in case of an articulatory-acoustic model in addition to generate an understandable and natural sounding acoustic speech signal. In case of the sub-laryngeal system the breathing activity during speech needs to be specified as a basis for calculating subglottal pressure and airflow. In case of the laryngeal system vocal cord tension and aperture needs to be specified as a basis for calculating the vocal fold vibrations and the phonatory acoustic signal. In case of the supra-laryngeal system a succession of vocal tract shapes (cavity shapes of oral, nasal, and pharyngeal cavity, Figure 1) needs to be specified for calculating the resulting acoustic speech signal.

Articulatory models mainly serve as a research tool 1) for defining a set of significant articulatory control parameters which is capable to control an articulatory model in all its aspects during speech production, 2) for verifying hypotheses concerning the neuromuscular and biomechanical properties of speech articulators, and 3) in case of articulatory-acoustic models to test acoustic and aerodynamic theories of speech production for generating realistic acoustic output based on the geometric data provided by the model.

First articulatory models were mechanical devices (e.g., Kempelen's speaking machine; von Kempelen, 1791, see also Dudley and Tarnoczy, 1950). Because most computerimplemented articulatory speech synthesizers currently do not allow real-time signal generation and because of the advance in developing anthropomorphic systems during last decades, the existence of robotic-mechanical reconstruction approaches for the human vocal tract, allowing a direct aerodynamic and acoustic signal generation should be mentioned here as well (e.g., the WASEDA anthropomorphic talking robot; Fukui et al., 2009). But these approaches still have difficulties to mimic the neuromuscular and biomechanical details of the human vocal apparatus and thus to model the geometrical details of articulators, of vocal tract shapes, and of articulator movements.

In this paper we focus on computer-implemented models beginning with models developed in the 1960s/1970s up to contemporary articulatory models and synthesizers which are developed to approach the goal of producing high-quality articulatory-acoustic signals and/or to reproduce the neuromuscular and biomechanical properties of articulators as close as possible. We include articulatory models with and without an acoustic module because some approaches mainly concentrate on the neuromuscular and biomechanical aspects while other approaches concentrate on the generation of acoustically relevant vocal tract geometries. Moreover, many articulatory models focus exclusively on modeling the supralaryngeal part of articulation, especially if an acoustic model part is not included. These articulatory models are included here as well.

\section{FEATURES FOR DIFFERENTIATING COMPUTER-IMPLEMENTED ARTICULATORY MODELS}

A (not necessarily complete) list of well published articulatory models is given in Table 1. These models can be differentiated with respect to a set of model features (columns of Table 1).

Two-dimensional models (e.g., Mermelstein, 1973; Maeda, 1990; Stark et al., 1999; Beautemps et al., 2001; Iskarous et al., 2003) generate mid-sagittal shapes of the vocal tract. While this geometrical information is the most relevant $2 \mathrm{D}$-information for many speech sounds there exist sounds like the laterals for which the midsagittal information is misleading. Laterals exhibit a midsagittal closure while the lateral parts of the tongue produce an opening for laminar air flow. Traditionally the area function is used as relevant information for calculating vocal tract acoustics from geometrical data. The area function represents the succession of cross-sectional areas occurring between glottis and mouth, perpendicular to the airflow within the vocal tract (area in $\mathrm{cm}^{2}$ as function of distance from glottis). There exist approaches to approximate area functions from midsagittal distances (Heinz and Stevens 1964; Perrier et al., 1992) but these approaches only approximate area functions roughly because the shape of the cross-sectional area of the vocal tract cavity perpendicular to the airflow varies strongly between glottis and mouth. Three-dimensional models (e.g., Buchaillard et al., 2009; Harandi et al., 2017) provide the full spatial information and are capable to calculate correct area functions in a straightforward way. But the goal of most 
TABLE 1 | List of computer-implemented articulatory models (rows) and criteria for differentiating articulatory models with respect to several features (rows; see text).

\begin{tabular}{|c|c|c|c|c|c|c|c|}
\hline Dim. & $\begin{array}{c}\text { Biomechanical vs. } \\
\text { geometrical vs. } \\
\text { statistical }\end{array}$ & $\begin{array}{c}\text { Number } \\
\text { of control } \\
\text { parameters }\end{array}$ & Data & $\begin{array}{c}\text { Acoustic } \\
\text { model }\end{array}$ & $\begin{array}{c}\text { Complete } \\
\text { VT }\end{array}$ & $\begin{array}{c}\text { Dynamic vs. } \\
\text { static, all sound } \\
\text { or less, } \\
\text { syllables }\end{array}$ & $\begin{array}{c}\text { Major } \\
\text { goal }\end{array}$ \\
\hline
\end{tabular}

\begin{tabular}{|c|c|c|c|c|c|c|c|c|}
\hline Badin et al. (2002) & 3D & $\begin{array}{l}\text { statistical, linear } \\
\text { component analysis }\end{array}$ & low $(<10)$ & $\begin{array}{l}\text { static MRI plus } \\
\text { video facial data }\end{array}$ & no & yes & dynamic & $\begin{array}{l}\text { identifying phonetic } \\
\text { and biomechanical } \\
\text { interpretable model } \\
\text { control parameters }\end{array}$ \\
\hline $\begin{array}{l}\text { Beautemps et al. } \\
\text { (2001) }\end{array}$ & $2 \mathrm{D}$ & $\begin{array}{l}\text { statistical, linear } \\
\text { component analysis }\end{array}$ & low (9) & $\begin{array}{l}\text { cine X-ray plus } \\
\text { video facial data }\end{array}$ & yes & yes & dynamic & $\begin{array}{l}\text { identifying the } \\
\text { degrees of freedom } \\
\text { (i.e., the number of }\end{array}$ \\
\hline
\end{tabular}
control parameters) for an articulatory model (statistical

\begin{tabular}{|c|c|c|c|c|c|c|c|c|}
\hline $\begin{array}{l}\text { Birkholz and Jackel } \\
\text { (2003), Birkholz } \\
\text { (2013) }\end{array}$ & $3 \mathrm{D}$ & $\begin{array}{l}\text { geometric; } \\
\text { parametric }\end{array}$ & middle (15) & static MRI data & yes & yes & dynamic & $\begin{array}{l}\text { high quality speech } \\
\text { synthesis }\end{array}$ \\
\hline $\begin{array}{l}\text { Buchaillard et al. } \\
\text { (2009) }\end{array}$ & $3 \mathrm{D}$ & $\begin{array}{l}\text { muscle force model; } \\
\text { biomechanical tissue } \\
\text { model }\end{array}$ & middle (11) & $\begin{array}{l}\text { static MRI and CT } \\
\text { data for vowels } \\
\text { (geometries); } \\
\text { EMG data } \\
\text { (muscle } \\
\text { activation) }\end{array}$ & yes & yes & static V-sounds & $\begin{array}{l}\text { muscle force levels for } \\
\text { different French } \\
\text { vowels }\end{array}$ \\
\hline Coker (1976) & $2 \mathrm{D}$ & $\begin{array}{l}\text { geometric; } \\
\text { parametric }\end{array}$ & low $(<10)$ & static X-ray data & yes & yes & dynamic & $\begin{array}{l}\text { speech synthesis by } \\
\text { rule; developing an } \\
\text { approach for } \\
\text { articulatory } \\
\text { commands }\end{array}$ \\
\hline $\begin{array}{l}\text { Dang and Honda } \\
\text { (2004) }\end{array}$ & $2 \mathrm{D}$ & $\begin{array}{l}\text { muscle force model; } \\
\text { biomechanical tissue } \\
\text { model }\end{array}$ & $\begin{array}{l}\text { middle (10 for } \\
\text { tongue) }\end{array}$ & static MRI data & no & $\begin{array}{l}\text { tongue }+\mathrm{VT} \\
\text { walls }\end{array}$ & $\begin{array}{l}\text { movements } \\
\text { towards V-and } \\
\text { C-sound } \\
\text { equilibrium } \\
\text { positions }\end{array}$ & $\begin{array}{l}\text { identifying agonist- } \\
\text { antagonist muscle } \\
\text { groups (muscle } \\
\text { synergies) for V- can } \\
\text { C-sounds }\end{array}$ \\
\hline Engwall (2003) & $3 \mathrm{D}$ & $\begin{array}{l}\text { statistical; ordered } \\
\text { linear factor analysis }\end{array}$ & low (6 for tongue) & $\begin{array}{l}\text { static MRI plus } \\
\text { EMA, EPG }\end{array}$ & no & tongue & $\begin{array}{l}\text { static V-and } \\
\text { C-sounds VC- } \\
\text { sequences with } \\
\mathrm{C}=\text { fricative }\end{array}$ & $\begin{array}{l}\text { identifying kinematic } \\
\text { model control } \\
\text { parameters; } \\
\text { developing methods } \\
\text { for including EMA and } \\
\text { EPG data for } \\
\text { modeling tongue } \\
\text { movements }\end{array}$ \\
\hline $\begin{array}{l}\text { Harandi et al. (2015), } \\
\text { Harandi et al. (2017) }\end{array}$ & 3D & $\begin{array}{l}\text { muscle activation + } \\
\text { force model; biome- } \\
\text { chanical tissue } \\
\text { model }\end{array}$ & $\begin{array}{l}\text { high ( } 21 \text { for } \\
\text { tongue and jaw) }\end{array}$ & $\begin{array}{l}\text { tagged MRI plus } \\
\text { cine MRI data }\end{array}$ & formants & $\begin{array}{l}\text { tongue }+\mathrm{VT} \\
\text { walls }\end{array}$ & $\begin{array}{l}\text { tongue forward- } \\
\text { backward } \\
\text { movement }\end{array}$ & $\begin{array}{l}\text { specifying speaker- } \\
\text { specific muscle } \\
\text { activation patterns } \\
\text { based on tagged and } \\
\text { cine MRI data }\end{array}$ \\
\hline Henke (1966) & $2 \mathrm{D}$ & $\begin{array}{l}\text { geometric; } \\
\text { parametric }\end{array}$ & $\begin{array}{l}\text { Non-parametric } \\
\text { "goal-seeking" } \\
\text { approach }\end{array}$ & cine X-ray data & $\begin{array}{l}\text { transfer } \\
\text { function }\end{array}$ & yes & dynamic & $\begin{array}{l}\text { specifying control } \\
\text { concepts for } \\
\text { articulatory } \\
\text { movements and } \\
\text { modeling } \\
\text { coarticulation }\end{array}$ \\
\hline Iskarous et al. (2003) & $2 \mathrm{D}$ & $\begin{array}{l}\text { geometric; } \\
\text { parametric }\end{array}$ & low $(<10)$ & $\begin{array}{l}\text { static X-ray data, } \\
\text { ultrasound, } \\
\text { static MRI }\end{array}$ & yes & yes & dynamic & $\begin{array}{l}\text { research tool; testing } \\
\text { gesture patterns by } \\
\text { perception }\end{array}$ \\
\hline Kröger et al. (2014) & $2 \mathrm{D}$ & $\begin{array}{l}\text { geometric; } \\
\text { parametric }\end{array}$ & low $(<10)$ & static MRI data & yes & yes & dynamic & $\begin{array}{l}\text { midsagittal views of } \\
\text { dynamic articulation } \\
\text { for teaching and as } \\
\text { tool in speech therapy }\end{array}$ \\
\hline
\end{tabular}


TABLE 1 | (Continued) List of computer-implemented articulatory models (rows) and criteria for differentiating articulatory models with respect to several features (rows; see text).

\begin{tabular}{|c|c|c|c|c|c|c|c|c|}
\hline & Dim. & $\begin{array}{c}\text { Biomechanical vs. } \\
\text { geometrical vs. } \\
\text { statistical }\end{array}$ & $\begin{array}{c}\text { Number } \\
\text { of control } \\
\text { parameters }\end{array}$ & Data & $\begin{array}{l}\text { Acoustic } \\
\text { model }\end{array}$ & $\begin{array}{c}\text { Complete } \\
\text { VT }\end{array}$ & $\begin{array}{l}\text { Dynamic vs. } \\
\text { static, all sound } \\
\text { or less, } \\
\text { syllables }\end{array}$ & $\begin{array}{l}\text { Major } \\
\text { goal }\end{array}$ \\
\hline $\begin{array}{l}\text { Maeda (1979), } \\
\text { Maeda (1990), Boe } \\
\text { et al. (1995) }\end{array}$ & $2 \mathrm{D}$ & $\begin{array}{l}\text { statistical; principal } \\
\text { component analysis; } \\
\text { growth model }\end{array}$ & $\begin{array}{l}\text { low }(7) \text {, see also } \\
\text { Toutios et al. } \\
(2011)\end{array}$ & cine X-ray data & yes & yes & dynamic & $\begin{array}{l}\text { research tool; } \\
\text { identification of model } \\
\text { control parameters }\end{array}$ \\
\hline $\begin{array}{l}\text { Mermelstein (1973), } \\
\text { Rubin et al. (1981) }\end{array}$ & $2 \mathrm{D}$ & $\begin{array}{l}\text { geometric; } \\
\text { parametric }\end{array}$ & low $(<10)$ & static X-ray data & yes & yes & VCV-sequences & $\begin{array}{l}\text { VCV-sequences; } \\
\text { coarticulation; } \\
\text { speech synthesis; } \\
\text { research tool }\end{array}$ \\
\hline Perrier et al. (2003) & $2 \mathrm{D}$ & $\begin{array}{l}\text { muscle activation + } \\
\text { force model (lambda } \\
\text { model); } \\
\text { biomechanical tissue } \\
\text { model }\end{array}$ & $\begin{array}{l}\text { low }(<10 \text { for } \\
\text { tongue })\end{array}$ & $\begin{array}{l}\text { qualitative } \\
\text { comparison with } \\
\text { CVC movement } \\
\text { data extracted } \\
\text { from literature }\end{array}$ & no & tongue & VCV-sequences & $\begin{array}{l}\text { VCV-sequences; C = } \\
\text { velar consonant; } \\
\text { tongue body } \\
\text { movement during C } \\
\text { (loops) }\end{array}$ \\
\hline $\begin{array}{l}\text { Sanguineti et al. } \\
\text { (1998) }\end{array}$ & $2 \mathrm{D}$ & $\begin{array}{l}\text { muscle activation + } \\
\text { force model (lambda } \\
\text { model); } \\
\text { biomechanical tissue } \\
\text { model }\end{array}$ & $\begin{array}{l}\text { middle and low } \\
\text { (17 muscles -> } 6 \\
\text { factors explain a } \\
\text { variance of } 75 \% \text {; } \\
\text { tongue + jaw + } \\
\text { hyoid) }\end{array}$ & cine X-ray data & no & $\begin{array}{l}\text { tongue, } \\
\text { hyoid, larynx, } \\
\text { lower jaw }\end{array}$ & $\begin{array}{l}\text { periodic jaw and } \\
\text { tongue } \\
\text { movements }\end{array}$ & $\begin{array}{l}\text { organization of } \\
\text { control signals; } \\
\text { dynamic behavior of } \\
\text { articulators; } \\
\text { identifying muscle } \\
\text { synergies }\end{array}$ \\
\hline Serrurier et al. (2019) & $2 \mathrm{D}$ & $\begin{array}{l}\text { statistical; principal } \\
\text { component analysis; } \\
\text { speaker-specific }\end{array}$ & middle (14) & static MRI data & no & yes & $\begin{array}{l}\text { static V-and } \\
\text { C-sounds }\end{array}$ & $\begin{array}{l}\text { estimation of control } \\
\text { parameters; based on } \\
11 \text { different speakers; } \\
\text { generating individual } \\
\text { models and a mean } \\
\text { speaker model }\end{array}$ \\
\hline $\begin{array}{l}\text { Serrurier and Badin } \\
\text { (2008) }\end{array}$ & $3 \mathrm{D}$ & $\begin{array}{l}\text { statistical; generic } \\
\text { surface triangular } \\
\text { mesh; principal } \\
\text { component analysis }\end{array}$ & low (2 for velum) & $\begin{array}{l}\text { static MRI and CT } \\
\text { plus EMA data }\end{array}$ & yes & $\begin{array}{l}\text { velum + } \\
\text { naso- } \\
\text { pharyngeal } \\
\text { wall }\end{array}$ & $\begin{array}{l}\text { static V- and } \\
\text { C-sounds }\end{array}$ & $\begin{array}{l}\text { identifying geometric } \\
\text { model control } \\
\text { parameters; modeling } \\
\text { velum movements } \\
\text { using additional EMA } \\
\text { data; resynthesis of } \\
\text { nasals }\end{array}$ \\
\hline Stark et al. (1999) & $2 \mathrm{D}$ & geometric & low $(<10)$ & cine X-ray data & yes & yes & dynamic & $\begin{array}{l}\text { speaker-specific } \\
\text { vocal tract } \\
\text { geometries for short } \\
\text { sound sequences }\end{array}$ \\
\hline Stone et al. (2018) & $1 \mathrm{D}$ & $\begin{array}{l}\text { parametric area- } \\
\text { function }\end{array}$ & middle (16) & static MRI data & yes & yes & dynamic & $\begin{array}{l}\text { high quality and real } \\
\text { time speech } \\
\text { synthesis }\end{array}$ \\
\hline $\begin{array}{l}\text { Story and Titze } \\
\text { (1998), Story (2005), } \\
\text { Story et al. (2018) }\end{array}$ & $1 \mathrm{D}$ & $\begin{array}{l}\text { parametric area- } \\
\text { function model; } \\
\text { speaker-dependent; } \\
\text { growth }\end{array}$ & $\begin{array}{l}\text { low }(<10) \text { for } \\
\text { static vowel } \\
\text { model; middle } \\
(14) \text { for dynamic } \\
\text { model }\end{array}$ & $\begin{array}{l}\text { static CT and MRI } \\
\text { data }\end{array}$ & yes & $\begin{array}{l}\text { area } \\
\text { functions } \\
\text { including } \\
\text { nasal tract }\end{array}$ & $\begin{array}{l}\text { dynamic (WV, } \\
\text { VCV and VCCV } \\
\text { utterances) or } \\
\text { static V- and } \\
\text { C-sounds }\end{array}$ & $\begin{array}{l}\text { articulatory-acoustic } \\
\text { relations for males/ } \\
\text { females for } \\
\text { newborns/children/ } \\
\text { adults; high-quality } \\
\text { speech synthesis of } \\
\text { isolated sounds and } \\
\text { of sound sequences }\end{array}$ \\
\hline $\begin{array}{l}\text { Wilhelms-Tricarico } \\
\text { (1996) }\end{array}$ & $3 \mathrm{D}$ & $\begin{array}{l}\text { muscle activation + } \\
\text { force model; } \\
\text { biomechanical tissue } \\
\text { model }\end{array}$ & $\begin{array}{l}\text { low (<10 at higher } \\
\text { control level); } \\
\text { middle }(<20 \text { at } \\
\text { lower control } \\
\text { level; tongue) }\end{array}$ & static MRI data & no & tongue & $\begin{array}{l}\text { static tongue } \\
\text { configurations }\end{array}$ & $\begin{array}{l}\text { physiologically based } \\
\text { computer simulation } \\
\text { of speech production; } \\
\text { research tool }\end{array}$ \\
\hline
\end{tabular}

current 3D-models is not the generation of acoustic speech signals but the detailed modeling of neuromuscular and biomechanical details of articulators. Moreover 3D-models are able to incorporate sagittal asymmetries in articulation which occur to a certain degree in normal as well as in disordered speech production. Beside $2 \mathrm{D}$-models representing the midsagittal plane 
and beside $3 \mathrm{D}$-models representing the complete shape of the vocal tract, even $1 \mathrm{D}$-models are available, which directly calculate and process the acoustically relevant area function (Story and Titze, 1998; Story, 2005; Stone et al., 2018; Story et al., 2018). “One dimension" in this case means that these models do not calculate the articulator shapes in a two-dimensional midsagittal plane or in the three-dimensional space, but just calculate one parameter, i.e., the (one-dimensional) distance between articulator and vocal tract wall as function of distance from the glottis along the midline of the vocal tract from glottis to mouth (e.g., Stone et al., 2018, p. 1381). These models are focusing directly on the acoustic effects of speech articulation.

First computer-implemented articulatory models were geometrical models (Henke 1966; Mermelstein 1973; Coker 1976; Rubin et al., 1981). Geometrical models are defined by making a priori assumptions concerning the basic geometries (parts of circles, straight lines) for constructing articulator shapes and concerning the set of control parameters. One of the most detailed geometrical 2D-model is that published by Iskarous et al. (2003). A further very detailed geometrical 3D-model has been developed by Birkholz and Jackel (2003). Both models are able to produce fluent speech and can be adapted to vocal tract geometries of different speakers. One main goal of geometrical models is to deliver a simple but phonetically and/or linguistically meaningful set of control parameters. Thus, the model of Iskarous et al. (2003) directly parameterizes degree and location of consonantal constrictions and the high-low, front-back, and rounded-unrounded dimension for vowels. Control parameter estimation can be done for this kind of model by fitting model vocal tract shapes to imaging data (contours stemming from X-ray, CT, EMA, or MRI measurements of natural speakers, see: Toutios et al., 2011; Ramanarayanan et al., 2013; Narayanan et al., 2014).

Statistical models are directly based on defined sets of imaging data. No a priori assumptions are made concerning articulators and their control parameters. Control parameters are defined here by using statistical procedures evaluating the variance of vocal tract shapes occurring in the data set. The data set can be a set of continuous movement data of whole sentences or a set of static imaging data representing a list of sound targets. The location of predefined flesh or tissue points of the articulators and vocal tract walls is extracted for each image and a principal component analysis is done on these sets of flesh point locations (Maeda, 1990; Badin et al., 2002; Engwall, 2003; Serrurier et al., 2019). In case of the Maeda model $88 \%$ of the variance of the flesh points, derived from a data set of 10 sentences uttered by a French speaker (519 images in total), can be explained by seven articulatory parameters, which are directly interpretable as physiological parameters for lips, tongue, jaw, and larynx (Boё et al., 1995).

The goal of geometric and statistical models is to parameterize vocal tract shapes with as few parameters as possible (see column 4 of Table 1: number of control parameters $<10$ for most of these models), but with enough flexibility to fit different speakers (adaptivity) as well as to fit the whole variety of vocal tract shapes occurring for each speaker in fluent speech. Most of the current statistical models are 2D-models (see Tab. 1) but a few
3D-models exist as well (Badin et al., 2002; Serrurier and Badin, 2008).

Biomechanical models approximate the anatomy and biomechanical properties of all vocal tract articulators. Its time-variant input is a vector of muscular activation levels leading to speech articulator movements and producing a succession of articulator displacements and thus of vocal tract shapes over time. Here, the body of articulators like tongue, lips, or velum is subdivided into $2 \mathrm{D}$ - or $3 \mathrm{D}$-finite elements with simple shapes. These elements are defined by a mesh of corner points. The current location or displacement of these tissue or mesh points and its displacement velocity and acceleration specifies all articulator movements. The forces acting on each mesh point and leading to mesh point movements result from active forces generated by the muscles and from passive forces resulting from biomechanical soft tissue properties. Some biomechanical models are 2D-models (e.g., Sanguineti et al., 1998; Perrier et al., 2003; Dang and Honda, 2004) but most biomechanical models are 3D-tongue models (e.g, Wilhelms-Tricarico, 1996; Buchaillard et al., 2009) or complete 3D-vocal tract models (e.g., Harandi et al., 2017). The definition of the 2D- or 3Dfinite element mesh is typically based on static X-ray or MRI data displaying the neutral or rest positioning of articulators. Because the set of muscles and its function during speech is complex, muscles are combined to synergetic acting muscle groups in many biomechanical models. These combinations of muscles to muscle groups allows a direct control of speech-like articulator movements like vocalic up-down and forward-backward movements of the tongue dorsum or like consonantal tongue tip elevation (e.g., Dang and Honda, 2004). The number of control parameters in general is higher in case of biomechanical models (see column 4 of Table 1: number of control parameters is in the range "middle" or "high", i.e., >10 control parameters), in order to be able to include all muscle activity values of all relevant muscles or muscle groups controlling different articulators.

The data set on which a model is based is of great importance for its quality and its empirical realism. In case of most models, static magnetic resonance imaging (MRI) data, static 2D X-ray, or static 3D-computer tomography (CT) data are used which display target vocal tract shapes of vocalic and consonantal speech sounds of one or more speakers (e.g., Mermelstein, 1973; Beautemps et al., 2001; Birkholz and Kröger, 2006). Dynamic X-ray movement data (cine-radio data; cineradiography), i.e., a succession of vocal tract shapes for complete utterances are rare because of ethical reasons due to the high radiation exposure. MRI movement data (cine MRI)which can be gathered with less health risks-are hard to acquire with a sufficient spatio-temporal resolution but are currently used more and more (Harandi et al., 2017; Carignan et al., 2021). In order to check movement features of a model EMA data (electromagnetic articulography), EMA data in combination with EPG data (electropalatography), or X-ray microbeam data can be used but these data give only selective punctual spatial information concerning the vocal tract shape (Westbury et al., 1990; Wrench and Hardcastle, 2000; Toutios et al., 2011). Moreover, tagged MRI in combination with cine MRI (2D) is 


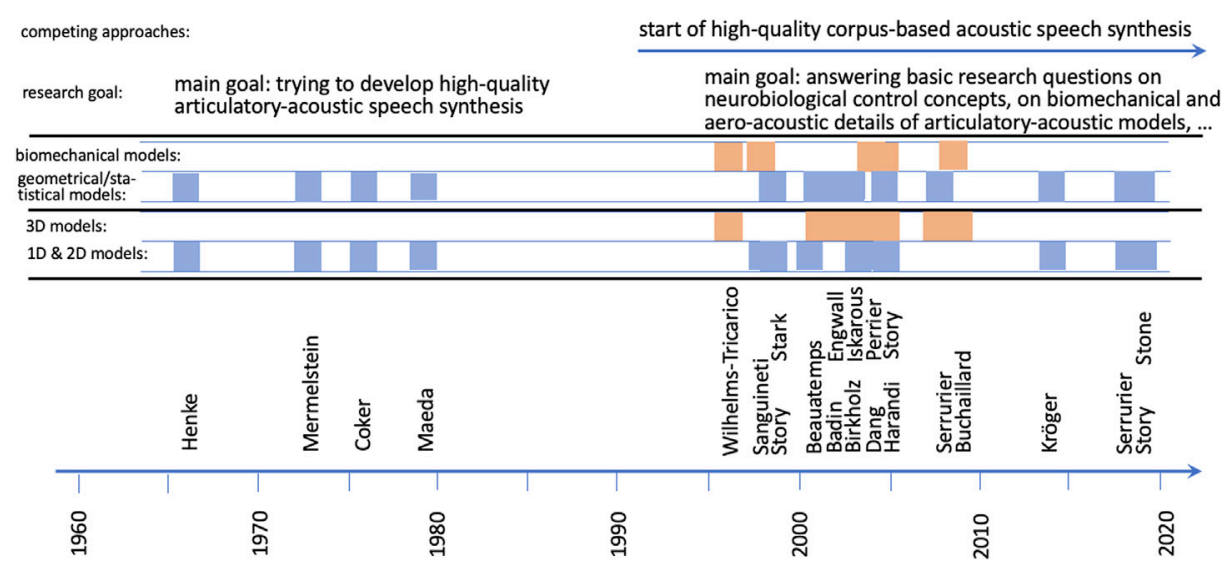

FIGURE 2| Visualization of the evolution of articulatory models over time. Models are cited here by the first author, as listed in Table 1. Main research goals and two criteria for differentiating articulatory models (biomechanical vs. geometrical and statistical models; 1D and 2D models vs. 3D models) are labeled and visualized.

capable of tracking movements of tissue points on the surface as well as inside an articulator and thus can give information concerning the displacement of finite element mesh points during connected speech (Stone et al., 2001; Harandi et al., 2017).

Some articulatory modeling approaches try to approach the goal not just to generate vocal tract shapes but in addition to generate acoustic speech signals based on the input control information (e.g., Rubin et al., 1981; Maeda, 1990; Iskarous et al., 2003; Birkholz, 2013; Story et al., 2018). The goal of older models was to reach high-quality speech synthesis using simple articulation-based control concepts. Later models mainly aim for unfolding articulatory-acoustic relations or want to check whether the implemented control concept results in correct audible speech movements. Acoustic models implemented in 2D-articulatory models calculate mainly pressure and flow changes along the direction of airflow and can be called onedimensional acoustic models while 3D-articulatory models can incorporate more complex $2 \mathrm{D}$ - or $3 \mathrm{D}$-acoustic models as well (Mullen et al., 2007; Speed et al., 2013).

Most articulatory models, especially those which aim to generate vocal tract shapes as well as acoustic speech signals model all articulators and thus generate the complete vocal tract shape. These models are mainly geometrical or statistical models (e.g., Rubin et al., 1981; Maeda, 1990; Iskarous et al., 2003; Birkholz, 2013) while most of the biomechanical models concentrate on modeling the tongue, its movements and its neuromuscular structure (e.g., Wilhelms-Tricarico 1996; Engwall, 2003; Perrier et al., 2003; Dang and Honda, 2004). Some models do not calculate an audible acoustic signal but the acoustic transfer function of the vocal tract or the formant pattern (Henke, 1966; Harandi et al., 2017).

A further criterion for differentiating articulatory models is whether they are able to generate static vocal tract shapes only or whether they are able to generate articulatory movement patterns. Most of the articulatory models generate dynamic vocal tract articulator movements. But some models just generate static vocalic vocal tract shapes because they concentrate on research questions concerning vowel systems (e.g., Buchaillard et al., 2009) or they concentrate on the generation of static vowel and consonant vocal tract shapes because of research questions concerning language-specific sound systems (e.g., Serrurier et al., 2019).

The last criterion for differentiating articulatory models listed in Tab. $\mathbf{1}$ is the question concerning the primary research goal for which a model is intended to be used. As mentioned earlier one of the goals in the early years of computational articulatory models (earlier than the last decade of the 20th century, Figure 2) was to generate high-quality speech synthesis on the basis of a relatively restricted but phonetically linguistically relevant set of articulatory control parameters following a rule system of intuitive and linguistically motivated commands.

But this goal is not reached yet and the paradigm for developing articulatory models changed towards modeling speech articulators in more detail on the biomechanical level and to extract neurobiologically relevant higher-level control commands for the generation of the complex muscle activation pattern for all vocal tract articulators and thus for the generation of speech articulator movements. This branch of models can be labeled as neurobiologically and biomechanically realistic models.

One further research goal which can be focused on by using articulatory models including a neurobiologically realistic control concept is to model speech acquisition. Because it is not possible to uncover the exact neural learning processes during learning tasks like babbling (i.e., exploring all articulatory and acoustic capabilities of the own vocal tract) or during learning tasks like imitation (i.e., trying to learn words from a caretaker in order to be able to start first trials of speech communication) as well as to uncover the microscopic aspects of the development of the human nervous system during the first years of life where speech acquisition mainly takes place, neurobiologically inspired computational control models including articulatory models as front-end devices for the generation of articulatory movement patterns and acoustic speech-like (and later speech) signals are helpful. These models are able to mimic learning processes during speech acquisition including sensorimotor 
learning and thus to unfold potential neural processes of speech learning. A review of this research is given by Pagliarini et al. (2021). The articulatory models used in this research area are mainly the Maeda (1990) model which can be downloaded as VTCalcs software (see VTCalcs, 2021) and the Birkholz (2013) model which can be downloaded as Vocal Tract Lab (see VocalTractLab, 2021).

\section{MODELING VOCAL TRACT AERODYNAMICS AND ACOUSTICS: THE SOUND SOURCES}

The quality of a synthetic acoustic speech signal strongly depends on the quality of the source signals. Sound sources occurring in speech production are the vibrating vocal folds leading to phonation in case of voiced sounds and further vocal tract constrictions leading to an increase in velocity of air flow and causing turbulent noise. While the vibrating vocal folds are labeled as primary sound source further constrictions within the vocal tract capable of producing turbulent noise are called secondary sound sources. Secondary sound sources appear e.g., in fricative sounds like/f/,/v/,/s/,/z/or/S/or/Z/(SAMPA symbols are used here, see SAMPA, 2021). Here, a vocal tract constriction is produced by an articulator approaching a vocal tract wall or a second articulator (e.g., lower lips approaching upper teeth or tongue tip approaching the alveolar ridge or hard palate) which causes an accelerated flow within and in front of the constriction (jet flow) and which leads to turbulent noise in front of the constriction. The glottis (glottal constriction) itself can produce turbulent noise as a side product during phonation or as a "stand alone sound" (glottal fricative/h/) if the vocal folds are adducted. Within the phonation mode the vocal folds exhibit oscillations leading to a (quasi-) periodic modulation of the glottal flow and subsequently to a (quasi-) periodic acoustic speech signal with a fundamental frequency reflecting the glottal vibration period. In order to model both types of sound sources adequately a detailed aerodynamic and aeroacoustic model needs to be incorporated as part of an articulatory speech synthesizer.

Aeroacoustics deals with the interaction of the flow mode of air (aerodynamics) and the sound mode of air (acoustics). While in case of aerodynamics an air volume is seen as incompressible including translational as well as rotational motion and where energy is transported by moving the whole air volume (convection), in case of acoustics an air volume is seen as compressible (local pressure and flow variations) and energy is transported here by sound wave propagation (e.g., Krane, 2005). While airflow (aerodynamics) is mainly considered as steady or quasi-steady (temporal variation of vocal tract constrictions like building, holding and release of a constriction appears in intervals of about $50 \mathrm{msec}$ or longer and thus reflect a periodicity below $20 \mathrm{~Hz}$ ), acoustic pressure and flow variations can be considered likewise as fast (above $20 \mathrm{~Hz}$ ), but the transition from aerodynamics to acoustics in terms of frequency or periodicity is fluent. In case of primary and secondary sound sources especially the energy transfer from air flow to acoustics in case of secondary sound sources and from air flow to the mechanical system of the vocal folds in case of the primary sound source needs to be modeled in-depth.

Because current simulation models of sound sources especially in case of the generation of turbulent noise do not yet provide satisfactory auditory results a lot of research is done using mechanical aeroacoustic models and theoretical approaches for the primary and secondary sound sources (e.g., McGowan, 1988; Pelorson et al., 1997; Krane, 2005; McGowan and Howe, 2012; McPhail et al., 2019; Motie-Shirazi et al., 2021). New simulation approaches have been developed including more detailed knowledge concerning aeroacoustic phenomena concerning secondary sound sources (e.g., Howe and McGowan, 2005) as well as concerning the primary sound source (e.g., Schickhofer and Mihaescu, 2020; Schoder et al., 2020) but these approaches are computationally complex and not integrated in articulatory speech synthesizers so far. A well elaborated acoustic model for articulatory speech synthesis including all relevant loss mechanisms important for a correct modeling of vocal tract acoustics and for steady state aerodynamics and which can be implemented in a time-domain reflection-type line analogue without high computational costs has been developed by Liljencrants (1985) and Liljencrants (1989) and an equivalent frequency domain approach has been published by Sondhi and Schroeter (1987). Both approaches are still widely used in articulatory speech synthesis systems. These types of models produce acceptable acoustic signal quality in case of voiced sounds and they allow the integration of noise source generators for modeling fricative sounds, plosive noise bursts, and glottal noise. The noise source amplitude is controlled here by the Reynolds number and the spectrum of the noise source is white or colored noise depending on the place of articulation. While these systems are one dimensional (only calculating pressure and flow along the vocal tract cavity midline from glottis to mouth eventually branched for including the nasal cavity) current solutions based on fluid dynamic approaches which model the three-dimensional wave propagation within the vocal tract are available as well (e.g., Huang et al., 2002; Levinson et al., 2012). To this day only few acoustic models including a detailed aeroacoustic concept are designed for articulatory speech synthesis because of their computational effort (Pelorson et al., 1994; Sinder et al., 1998; Narayanan and Alwan, 2000; Birkholz et al., 2007; Zappi et al., 2016; Pont et al., 2018).

In case of the primary sound source, we can separate models directly prescribing a glottal cross-sectional area as function of time and models including a self-oscillating glottis module. While in the first category of models the glottal flow can be calculated directly (e.g., Titze, 1989; McGowan and Howe, 2012), a complete mechanical model of the vocal folds needs to be implemented in case of the second category of models in order to calculate the vocal fold vibration pattern and the glottal area as function of time first before the glottal air flow can be calculated. Here the oscillatory motion pattern of the vocal folds results from the interactions of this mechanical system with the aerodynamic system (self-oscillating glottis models, e.g., Ishizaka and Flanagan, 1972; Story and Titze, 1995; Avanzini et al., 2006; Tao et al., 2006; Elie and Laprie, 2016; Maurerlehner et al., 2021). 


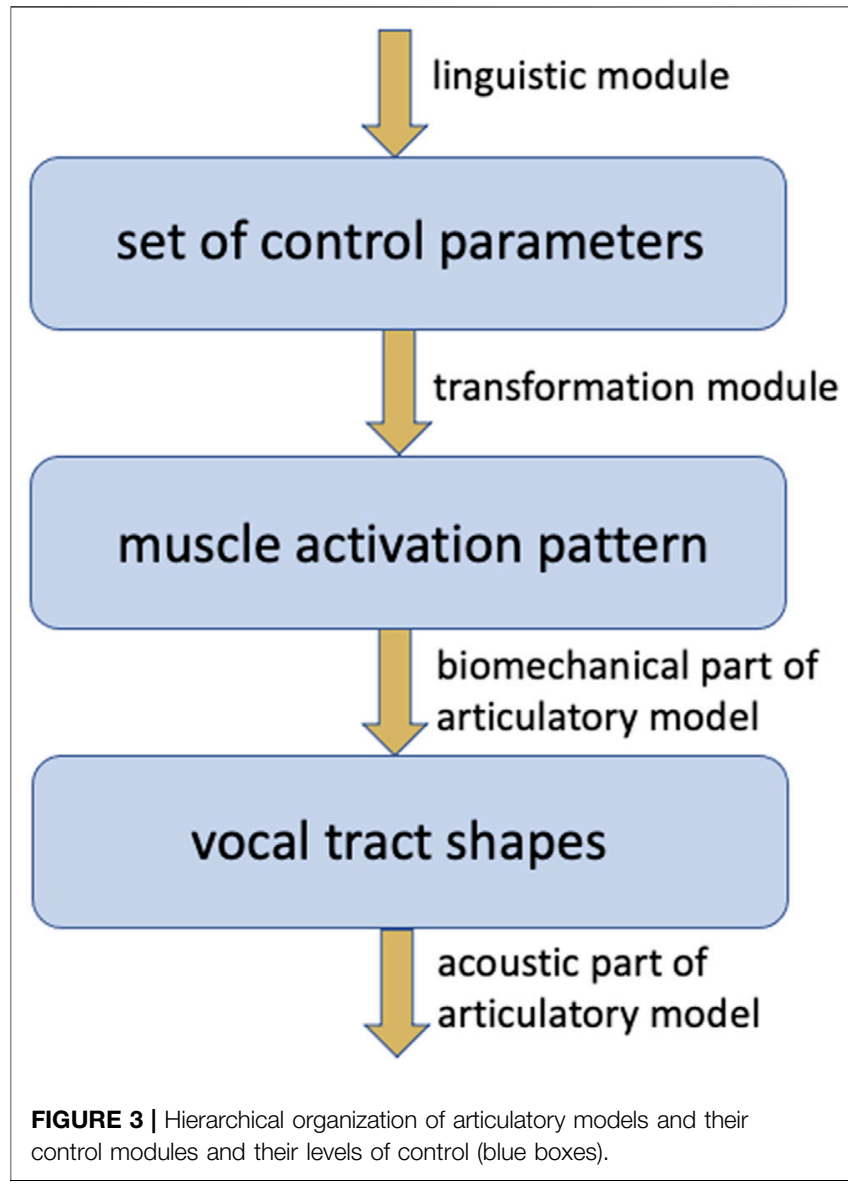

In case of both models aeroacoustic effects are important mainly for shaping the waveform of the glottal flow (e.g., McGowan and Howe, 2012) but aerodynamic and aeroacoustic effects can influence the pressure distribution along the glottal constriction as well and thus influence the aerodynamic forces acting on the vocal folds and thus influencing the glottal area oscillation pattern (Pelorson et al., 1994; McPhail et al., 2019).

In order to be able to calculate the air flow in the vocal tract, first of all the subglottal pressure must be determined. The mean subglottal pressure occurring in speech production for example occurring over syllable-level time intervals is mainly a function of volume change of the lung during expiration (e.g., Tanihara et al., 2018) and together with the quasi-steady air flow it in addition depends on the mean aerodynamic resistance resulting from the glottal constriction and the vocal tract constrictions occurring downstream towards the mouth. Thus, a sub-laryngeal system including a lung model controlled by articulatory parameters like lung volume or lung force (McGowan and Saltzman, 1995) together with a laryngeal system including a physiologically based vocal fold model controlled by articulatory parameters like glottal aperture and vocal fold tension (e.g., Ishizaka and Flanagan, 1972) together with a supra-laryngeal articulatoryacoustic system including aeroacoustics as discussed above is needed in order to complete an articulatory-acoustic speech production model from the aerodynamic point of view.

\section{AN OPEN QUESTION: MUSCLE GROUPS, MUSCLE ACTIVATION PATTERNS, AND CONCEPTS FOR ARTICULATORY CONTROL COMMANDS}

A crucial problem concerns the set of parameters controlling an articulatory model. The set of control parameters should be as small as possible and should be intuitive in the sense that each parameter is interpretable at the articulatory-phonetic level (e.g., location and degree of consonantal constriction, vocalic dimensions like front-back, low-high, rounded unrounded). Moreover, this set of control parameters should be neurobiologically plausible. It should be able to extract this set of parameters from muscle activation patterns and vice versa, it should be possible to transform each pattern of control parameters into a muscle activation pattern which controls the articulators and thus completely describes the displacements or movements of all articulators (Figure 3). In a neurobiologically grounded modeling approach the activation of a higher level description of speech articulation (which should be transformable into a vector of model control parameter values for each point in time) occurs within the cortical premotor area while the more complex muscle activation pattern is activated within the primary motor area for each utterance.

It is not possible to extract such a set of neurobiologically plausible control parameter patterns in a straightforward way in vivo because we cannot uncover all details of the human cortical and subcortical neural network which is responsible for speech processing. A prerequisite for extracting control parameters indirectly from models is that we have available a detailed biomechanical articulatory model including a detailed modelling concept for articulator tissues and for all muscles controlling the articulators. If we can develop a control concept for such a model which leads to natural articulatory speech movement patterns and which exhibits different control parameters for different linguistic goals (e.g., consonantal versus vocalic movement patterns) it can be concluded that the appropriate set of control parameters is a promising candidate to be incorporated in a neural control concept.

A detailed model for relating muscle activation, muscle force, and muscle length is the $\lambda$ model (Feldman et al., 1990) which has been applied to speech articulation (Sanguineti et al., 1998; Perrier et al., 2003). In this approach muscle activation results from an external activation control signal as well as from current muscle length and rate change of length. Thus, neuromuscular activation depends on a control signal (muscle activation patterns generated at the primary motor cortex) and on proprioceptive feedback. On this basis muscle force can be calculated from the external muscle activation control signal in combination with information about muscle length and its rate change. It is concluded that each muscle can be controlled effectively by specifying its threshold muscle length. This set of threshold muscle length, labeled as set of $\lambda$ 's, determines the current equilibrium position of all articulators and is used in this approach as an equivalent to muscle activation patterns. 
In all muscle-based biomechanical approaches (e.g., Wilhelms-Tricarico, 1996) including the $\lambda$ model, active stress of muscle tissue results from neuromuscular activation. This stress is muscle force per cross-sectional area of all muscle fibers of a muscle and leads to muscle contraction, i.e., change in muscle length. Contrariwise, passive stress and strain of muscle tissue and other tissues inside and at the surface of articulators results from deformation.

It is assumed that the set of central control parameters is presumably organized into a number of different combinations of threshold muscle lengths and their change. Thus, different muscles or parts of muscles (macro-fibers of muscles) together form synergies for initiating movement primitives or elementary motor behaviors. Movement primitives are identified by Sanguineti et al. (1998) for different articulators like jaw and tongue dorsum. Perrier et al. (2003, p. 1589) defines the central control commands directly as sets of $\lambda$ 's or as "targets" or "postures" which represent specific equilibrium positions for all articulators for different speech sounds. Movements are produced by continuously varying the set of $\lambda$ 's from one sound target to the next sound target. Because the set of $\lambda$ 's defines the location of all articulators completely, different sound targets need to be specified for consonants in order to reflect the coarticulatory influence of neighboring vowels while each vowel can be represented by one target. A concrete set of $\lambda$ 's is estimated for three French vowel realizations of/i/,/a/and/u/for the tongue by Buchaillard et al. (2009). $\lambda$ values are given here as a percentage of muscle length with respect to the muscles rest length defining the rest position of the tongue.

A set of movement primitives resulting from specific subsets of muscles or parts of muscles are called muscle groups is suggested by Dang and Honda (2004). These muscle groups are activated by defining co-contraction activation levels for agonist-antagonist pairs or triplets of muscles. Muscle groups and corresponding movement patterns are identified for independent tongue dorsum and tongue tip movements here (vocalic and consonantal movement primitives). This approach allows to specify subsets of muscles for example for defining vocalic tongue dorsum or consonantal tongue tip movements and consonantal movements can be superimposed on underlying vocalic movements in this approach.

Harandi et al. (2017) present a data driven approach for estimating muscle force and muscle activation patterns based on cine MRI and tagged MRI data. Here muscle activation patterns are estimated for the whole set of muscles for each point in time. Higher-level control concepts are not postulated.

A non-muscle-based model for controlling a geometrical articulatory model (Iskarous et al., 2003) is given by Ramanarayanan et al. (2013). Here, a pattern of linguistically defined gestures as postulated in the framework of Articulatory Phonology (Browman and Goldstein 1992) is activated for controlling all speech articulators. Here, gesture-based activation patterns establish the central control structure. But a (lower-level) biomechanical muscle-based activation level is not included. The approach directly defines (higher-level) activation patterns for gestures, which are later labeled as articulatory movement primitives by Ramanarayanan et al. (2013, p. 1378):
"Articulatory movement primitives may be defined as a dictionary or template set of articulatory movement patterns in space and time, weighted combinations of the elements of which can be used to represent the complete set of coordinated spatio-temporal movements of vocal tract articulators required for speech production." These movement primitives or gestures are defined as coordinative structures based on synergy principles by controlling the movements of one or more articulators and can be converted into movement pattern by using the task-dynamics approach (Saltzman and Munhall 1989). Based on an analysis of EMA and dynamic MRI data using matrix factorization techniques seven articulatory primitives are identified by Ramanarayanan et al. (2013), i.e., labial, apical and dorsal constriction gestures in context of front or back vowels. All models including detailed biomechanical muscle models and a muscular activation level are labeled in column 3 of table $\mathbf{1}$ as "biomechanical".

A blueprint for the organization of neural control in speech production is given by the DIVA model (Directions Into Velocities of Articulators, see Guenther 2006, Bohland et al., 2010, and Guenther and Vladusich 2012). This approach differentiates a higher level neural representation of speech units like syllable called speech sound map located in the premotor cortex and a lower level neural representation of these units called articulatory map located in the primary motor cortex. Bohland et al. (2010) extended the DIVA approach towards the GODIVA-model (Gradient Order DIVA model) which in addition gives a detailed description of the planning process of articulation, i.e., how planning units like syllables, words or short phrases can be parsed from the flow of linguistic-phonological information. But the concrete implementation of the DIVA model leads to control signals for a statistical model (Maeda model, see Maeda, 1979, Maeda, 1990 and Boë et al., 1995) which does not control a detailed muscle-based biomechanical articulatory model.

\section{DISCUSSION: LIMITATIONS AND FUTURE DIRECTIONS FOR MODELING SPEECH ARTICULATION}

One of the main problems in developing articulatory models is the lack in articulatory data exhibiting a sufficient spatiotemporal resolution. Static MRI and X-ray (or CT) data give a sufficient spatial resolution in order to extract the surface shape of all articulators and vocal tract walls with a mean error of around $1 \mathrm{~mm}$ but a sufficient temporal resolution is only reached by some highly specialized research groups (e.g., Fu et al., 2017; Carignan et al., 2021). In case of midsagittal 2D-data a resolution of about $50 \mathrm{~Hz}$ (time interval of $20 \mathrm{msec}$ ) as is reported for cine X-ray tracking is not sufficient in case of tracking and modeling for example consonantal closing-opening movements. The temporal resolution for tracking speech movements should reach $10-5 \mathrm{msec}(100-200 \mathrm{~Hz})$. In the case of 3D-data most measurements extract static vocal tract geometries because the data acquisition procedure still takes seconds in case of MRI. In some laboratories cine 2D-MRI data can be acquired already with 
rates of $12.5-23 \mathrm{~Hz}(80-43 \mathrm{msec})$ with a spatial resolution of about $2.5 \mathrm{~mm}$ (Narayanan et al., 2014). Thus, EMA data are added in order to get a sufficient temporal resolution. Here, 12 flesh points or more can be tracked with a temporal resolution of $200 \mathrm{~Hz}$ and higher and with a spatial resolution below $1 \mathrm{~mm}$ (Richmond et al., 2011). EMA in principle is not limited to measuring 12 flesh points but gluing coils on articulators (tongue, lips) is tricky and limits the total number of coils that can be glued on. Moreover, EMA receiver coils with its diameter of about $3 \mathrm{~mm}$ may influence articulation. Recently even cine MRI increases dramatically in temporal resolution up to $50 \mathrm{~Hz}$ $(20 \mathrm{msec})$ with a spatial resolution of $1.4 \mathrm{~mm}$ including a postprocessing resampling procedure leading to an even higher temporal resolution up to a factor 10 (Carignan et al., 2021) or up to $166 \mathrm{~Hz}(6 \mathrm{msec})$ with a spatial resolution of $2.2 \mathrm{~mm}$ (Fu et al., 2017).

Current biomechanical models mainly concentrate on modeling jaw and tongue. A complete model including all articulators should be established, but the main problem with biomechanical models is its control. A huge number of muscles needs to be modelled and thus the muscle activation pattern controlling articulation over time is complex. It is assumed that this lower-level control information is generated from a higherlevel motor command level, but there exists no standard approach how to define synergies or coordinative structures for speech articulation and a widely accepted standard higher-level control concept for speech articulation still needs to be developed.

As mentioned above, a very comprehensive and detailed neural model for speech production is the DIVA model (Guenther, 2006), but even this model does not include a detailed muscle-based biomechanical model. This may result from the fact that in case of human sound production we do not find a one-to-one relation of muscles and speech sounds. Even the production of a single speech sound (a single configuration of speech articulators) requires a synergistic cooperation of different groups of muscles (cf. Dang and Honda, 2004) while for example in the case of birdsongs, sounds are producible by one-to-one innervations of vocal muscles (Adam et al., 2021).

Already at the end of the last century leading researchers in speech production stated: "It has been hoped for decades that speech synthesis based on articulatory geometry and dynamics would result in a breakthrough in quality and naturalness of speech synthesis, but this has not happened. It is now possible to generate high quality synthetic speech, such as with the Klatt synthesizer, by modeling only the properties (spectral, etc.) of the output signal." (Wilhelms-Tricarico and Perkell 1997 , p. 222). During the following decades the situation has not changed much for articulatory-acoustic speech synthesis, while the quality of acoustic corpus-based speech synthesis increased dramatically towards nearly natural (Zen et al., 2009; Kahn and Chitode, 2016, and see research goals in Figure 2). Thus, the problem of high-quality speech synthesis is solved from the viewpoint of engineering but increasing the quality of articulatory-acoustic speech synthesis should be a side product if more knowledge is available concerning natural movement generation for speech articulators and if the remaining research questions in aeroacoustic signal generation are solved.

But nevertheless, one remaining goal of modeling speech production including speech articulation will be to reach highquality speech synthesis. To reach this goal will be a step-by-step procedure which concerns all domains of the speech production process: 1) More anatomical details needs to be included in modeling, e.g., concerning the 3D-shape of vocal tract cavities and its changes during speaking (e.g., Vampola et al., 2015; Traser et al. 2017; Birkholz and Drechsel, 2021). 2) More knowledge is needed concerning the neurophysiological processes of controlling the movements of vocal tract organs during speech production at a higher control level (e.g., Guenther, 2006; Bohland et al., 2010; Guenther and Vladusich, 2012) as well as at the neuromuscular level at which neural activation causes articulator motion (e.g. Buchaillard et al., 2009). 3) More knowledge is needed especially concerning the phonation process in order to be able to produce individual and naturally sounding voice qualities (e.g., Vasudevan et al., 2017; Maurerlehner et al., 2021). 4) More acoustic and aeroacoustic knowledge is needed for improving the quality of acoustic signal generation and signal modification within the vocal tract (Zappi et al., 2016; Schoder et al., 2020).

Last but not least an attempt will be made here to answer the three core questions raised in the abstract concerning improvement of the generated acoustic signal quality and concerning the biological realism of the control concept and concerning the articulatory model. 1) Currently there exists no concrete concept for modeling the underlying neural organization controlling speech articulation. This concept should be neurobiologically grounded, should be activated by linguistic information like a phonological sound chain augmented by prosodic information, and should generate a motor description of the utterance under production. This kind of information is generated by gesture scores as defined by Ramanarayanan et al. (2013). But a neurobiological realization and implementation of gesture scores for example in a neural speech production model as well as the realization of a comprehensive approach for generating muscle activation patterns from gesture scores and its incorporation in a complete sensorimotor model of speech production has not yet been realized yet. This should be one of the next steps in developing control concepts for articulatory speech synthesis and for developing speech production models in general.

2) A lot of approaches are available for modeling speech articulators like tongue, lips, velum etc. and their movements. There are geometrical, statistical, or biomechanical approaches as discussed in this paper. In contrast to geometrical and statistic approaches, which are already usable as part of articulatory speech synthesizers (e.g., Birkholz model, see VocalTractLab, 2021; Maeda model as part of the DIVA speech production model, see VTCalcs, 2021) the next step or goal should be to establish comprehensive biomechanical and neurobiologically plausible models capable of generating speech movements for a complete set of vocal tract articulators and thus to establish biomechanical models capable for generating a temporal succession of complete vocal tract cavity shapes (vocal tract 
geometries) as a basis for calculating the acoustic speech signal (e.g., Vogt et al., 2005; ArtiSynth, 2021). 3) Beside modeling articulatory movement patterns and their control, the improvement of the acoustic signal generation within the vocal tract is a further goal. As already discussed above a lot of work is currently done in order to improve the modeling of the primary sound source by developing complex self-oscillating vocal fold models and their interaction with the aerodynamic system, in order to improve the modeling of secondary sound sources by unfolding the aeroacoustic principles of noise generation which in principle occur at all vocal tract constrictions, and in order to improve the quality of the acoustic signal modification in the vocal tract by using sophisticated acoustic/aeroacoustic modeling approaches.

But all these steps increase the computational costs and thus bring us far away from real-time applications which of course should be a further goal even for articulatory speech synthesis. Beside increasing naturalness of speech synthesis by using exclusively biologically motivated production

\section{REFERENCES}

Adam, I., Maxwell, A., Rößler, H., Hansen, E. B., Vellema, M., Brewer, J., et al. (2021). One-to-One Innervation of Vocal Muscles Allows Precise Control of Birdsong. Curr. Biol. 31, 3115-3124. doi:10.1016/j.cub.2021.05.008

ArtiSynth (2021). A 3D Biomechanical Modeling Toolkit (Www Quotation from 2021-10-27). Available at: https://www.artisynth.org/Software/ModelsDownload Accessed: October 15, 2021..

Avanzini, F., Maratea, S., and Drioli, C. (2006). Physiological Control of LowDimensional Glottal Models with Applications to Voice Source Parameter Matching. Acta Acustica united with Acustica 92, 731-740.

Badin, P., Bailly, G., Revéret, L., Baciu, M., Segebarth, C., and Savariaux, C. (2002). Three-Dimensional Linear Articulatory Modeling of Tongue, Lips and Face, Based on MRI and Video Images. J. Phonetics 30, 533-553. doi:10.1006/jpho. 2002.0166

Beautemps, D., Badin, P., and Bailly, G. (2001). Linear Degrees of freedom in Speech Production: Analysis of Cineradio- and Labio-Film Data and Articulatory-Acoustic Modeling. The J. Acoust. Soc. America 109, 2165-2180. doi:10.1121/1.1361090

Birkholz, P., and Jackel, D. (2003). “A Three-Dimensional Model of the Vocal Tract for Speech Synthesis," in Proceedings of the 15th International Congress of Phonetic Sciences - ICPhS'2003, 3-9 August 2003 (Barcelona, Spain), 2597-2600.

Birkholz, P., and Kröger, B. J. (2006). "Vocal Tract Model Adaptation Using Magnetic Resonance Imaging," in Proceedings of the 7th International Seminar on Speech Production, Ubatuba-SP, Brazil, 13-15 December 2006, Belo Horizonte, Brazil (, 493-500.

Birkholz, P., and Drechsel, S. (2021). Effects of the Piriform Fossae, Transvelar Acoustic Coupling, and Laryngeal wall Vibration on the Naturalness of Articulatory Speech Synthesis. Speech Commun. 132, 96-105. doi:10.1016/j. specom.2021.06.002

Birkholz, P., Jackel, D., and Kroger, B. J. (2007). Simulation of Losses Due to Turbulence in the Time-Varying Vocal System. IEEE Trans. Audio Speech Lang. Process. 15, 1218-1226. doi:10.1109/tasl.2006.889731

Birkholz, P. (2013). Modeling Consonant-Vowel Coarticulation for Articulatory Speech Synthesis. Plos One 8, e60603. doi:10.1371/journal.pone.0060603

Boë, L-J., Gabioud, B., and Perrier, P. (1995). The SMIP: An Interactive Articulatory-Acoustic Software for Speech Production Studies. Bull. de la Commun. Parlée 3, 137-154. (Grenoble, France).

Bohland, J. W., Bullock, D., and Guenther, F. H. (2010). Neural Representations and Mechanisms for the Performance of Simple Speech Sequences. J. Cogn. Neurosci. 22 (7), 1504-1529. doi:10.1162/jocn.2009.21306 principles the ultimate benchmark for the quality of articulatory speech synthesizers is the naturalness of the generated acoustic speech signal. While for example articulatory movement patterns like mouth or tongue movements may be assessed relatively easily as natural by our visual perceptual system this is not the case for the auditory perception of acoustic speech signals. Thus, the ultimate challenge for the developers of speech synthesis systems is the auditory evaluation of the produced speech signals and as each developer knows, the generation of not only understandable but also natural speech is the most complex and most challenging goal in developing and improving speech synthesis systems.

\section{AUTHOR CONTRIBUTIONS}

The author confirms being the sole contributor of this work and has approved it for publication.

Browman, C. P., and Goldstein, L. (1992). Articulatory Phonology: An Overview. Phonetica 49, 155-180. doi:10.1159/000261913

Buchaillard, S., Perrier, P., and Payan, Y. (2009). A Biomechanical Model of Cardinal Vowel Production: Muscle Activations and the Impact of Gravity on Tongue Positioning. J. Acoust. Soc. Am. 126, 2033-2051. doi:10.1121/1.3204306

Carignan, C., Coretta, S., Frahm, J., Harrington, J., Hoole, P., Joseph, A., et al. (2021). Planting the Seed for Sound Change: Evidence from Real-Time MRI of Velum Kinematics in German. Language 97 (2), 333-364. doi:10.1353/lan.2021.0020

Coker, C. H. (1976). A Model of Articulatory Dynamics and Control. Proc. IEEE 64, 452-460. doi:10.1109/proc.1976.10154

Dang, J., and Honda, K. (2004). Construction and Control of a Physiological Articulatory Model. J. Acoust. Soc. America 115, 853-870. doi:10.1121/1. 1639325

Dudley, H., and Tarnoczy, T. H. (1950). The Speaking Machine of Wolfgang von Kempelen. J. Acoust. Soc. America 22, 151-166. doi:10.1121/1.1906583

Elie, B., and Laprie, Y. (2016). "A Glottal Chink Model for the Synthesis of Voiced Fricatives," in Proceedings of the 2016 IEEE International Conference on Acoustics, Speech and Signal Processing (ICASSP), Shanghai, China, 20-25 March 2016, 5240-5244. doi:10.1109/ICASSP.2016.7472677

Engwall, O. (2003). Combining MRI, EMA and EPG Measurements in a ThreeDimensional Tongue Model. Speech Commun. 41, 303-329. doi:10.1016/s01676393(02)00132-2

Feldman, A. G., Adamovich, S. V., Ostry, D. J., and Flanagan, J. R. (1990). “The Origin of Electromyograms - Explanations Based on the Equilibrium Point Hypothesis," in Multiple Muscle Systems: Biomechanics and Movement Organization. Editors J Winters and S Woo (London: Springer), 195-213. doi:10.1007/978-1-4613-9030-5_12

Fu, M., Barlaz, M. S., Holtrop, J. L., Perry, J. L., Kuehn, D. P., Shosted, R. K., et al. (2017). High-Frame-Rate Full-Vocal-Tract 3D Dynamic Speech Imaging. Magn. Reson. Med. 77, 1619-1629. doi:10.1002/mrm.26248

Fukui, K., Ishikawa, Y., Ohno, K., Sakakibara, N., Honda, M., and Takanishi, A. (2009). "Three Dimensional Tongue with Liquid Sealing Mechanism for Improving Resonance on an Anthropomorphic Talking Robot," in Proceedings of the 2009 IEEE/RSJ International Conference on Intelligent Robots and Systems, St Louis, Missouri, USA, 10-15 October 2009, 5456-5462. doi:10.1109/IROS.2009.5353983

Guenther, F. H. (2006). Cortical Interactions Underlying the Production of Speech Sounds. J. Commun. Disord. 39, 350-365. doi:10.1016/j.jcomdis.2006.06.013

Guenther, F. H., and Vladusich, T. (2012). A Neural Theory of Speech Acquisition and Production. J. Neurolinguist. 25, 408-422. doi:10.1016/j.jneuroling.2009. 08.006

Harandi, N. M., Woo, J., Stone, M., Abugharbieh, R., and Fels, S. (2017). Variability in Muscle Activation of Simple Speech Motions: A Biomechanical Modeling Approach. J. Acoust. Soc. America 141, 2579-2590. doi:10.1121/1.4978420 
Harandi, N. M., Stavness, I., Woo, J., Stone, M., Abugharbieh, R., and Fels, S. (2015). Subject-Specific Biomechanical Modelling of the Oropharynx: Towards Speech Production. Comput. Methods Biomech. Biomed. Eng. Imaging Vis. 5, 416-426. doi:10.1080/21681163.2015.1033756

Heinz, J. M., and Stevens, K. N. (1964). On the Derivation of Area Functions and Acoustic Spectra from Cinéradiographic Films of Speech. J. Acoust. Soc. America 36, 1037-1038. doi:10.1121/1.2143313

Henke, W. L. (1966). Dynamic Articulatory Model of Speech Production Using Computer Simulation. Doctoral thesis. Cambridge, US: MIT.

Howe, M. S., and McGowan, R. S. (2005). Aeroacoustics of [s]. Proc. R. Soc. A. 461, 1005-1028. doi:10.1098/rspa.2004.1405

Huang, J., Levinson, S., Davis, D., and Slimon, S. (2002). "Articulatory Speech Synthesis Based upon Fluid Dynamic Principles," in Proceedings of the 2002 IEEE International Conference on Acoustics, Speech, and Signal Processing, Orlando, Florida, USA, 13-17 May 2002, I-445-I-448. doi:10.1109/ICASSP. 2002.5743750

Ishizaka, K., and Flanagan, J. L. (1972). Synthesis of Voiced Sounds from a TwoMass Model of the Vocal Cords. Bell Syst. Tech. J. 51, 1233-1268. doi:10.1002/j. 1538-7305.1972.tb02651.x

Iskarous, K., Goldstein, L., Whalen, D., Tiede, M., and Rubin, P. (2003). "CASY: The Haskins Configurable Articulatory Synthesizer," in Proceedings of the 15th International Congress of Phonetic Sciences (Spain: Barcelona), 185-188.

Kahn, R. A., and Chitode, J. S. (2016). Concatenative Speech Synthesis: A Review. Int. J. Comput. Appl. 136, 1-6. doi:10.5120/ijca2016907992

Krane, M. H. (2005). Aeroacoustic Production of Low-Frequency Unvoiced Speech Sounds. J. Acoust. Soc. America 118, 410-427. doi:10.1121/1. 1862251

Kröger, B. J., Bekolay, T., and Eliasmith, C. (2014). "Modeling Speech Production Using the Neural Engineering Framework," in Proceedings of CogInfoCom 2014, 5-7 November 2014, Vetri sul Mare, Italy, 203-208. doi:10.1109/ CogInfoCom.2014.7020446

Levinson, S., Davis, D., Slimon, S., and Huang, J. (2012). Articulatory Speech Synthesis from the Fluid Dynamics of the Vocal Apparatus. San Rafael, CA: Morgan \& Claypool.

Liljencrants, J. (1985). Speech Synthesis Wit Ha Reflection-Type Line Analog. Dissertation. Stockholm: Royal Institute of Technology.

Liljencrants, J. (1989). "Numerical Simulation of Glottal Flow," in Vocal Fold Physiology: Acoustics, Perception and Physiological Aspects of Voice Mechanisms. Editors J. Gauffin and B. Hammarberg (San Diego, CA: Singular Pub), 99-104.

Maeda, S. (1979). An Articulatory Model of the Tongue Based on a Statistical Analysis. J. Acoust. Soc. America 65, S22. doi:10.1121/1.2017158

Maeda, S. (1990). "Compensatory Articulation during Speech: Evidence from the Analysis and Synthesis of Vocal-Tract Shapes Using an Articulatory Model," in Speech Production and Speech Modelling. Editors WJ Hardcastle and A Marchal (Dordrecht, Netherlands: Kluwer Academic), 131-149. doi:10.1007/978-94009-2037-8_6

Maurerlehner, P., Schoder, S., Freidhager, C., Wurzinger, A., Hauser, A., Kraxberger, F., et al. (2021). Efficient Numerical Simulation of the Human Voice. Elektrotech. Inftech. 138, 219-228. doi:10.1007/s00502-021-00886-1

McGowan, R. S. (1988). An Aeroacoustic Approach to Phonation. J. Acoust. Soc. America 83, 696-704. doi:10.1121/1.396165

McGowan, R. S., and Howe, M. S. (2012). Source-Tract Interaction with Prescribed Vocal Fold Motion. J. Acoust. Soc. America 131, 2999-3016. doi:10.1121/1. 3685824

McGowan, R. S., and Saltzman, E. L. (1995). Incorporating Aerodynamic and Laryngealcomponents into Task Dynamics. J. Phonetics 23, 255-269. doi:10. 1016/s0095-4470(95)80047-6

McPhail, M. J., Campo, E. T., and Krane, M. H. (2019). Aeroacoustic Source Characterization in a Physical Model of Phonation. J. Acoust. Soc. America 146, 1230-1238. doi:10.1121/1.5122787

Mermelstein, P. (1973). Articulatory Model for the Study of Speech Production. J. Acoust. Soc. America 53, 1070-1082. doi:10.1121/1.1913427

Motie-Shirazi, M., Zañartu, M., Peterson, S. D., and Erath, B. D. (2021). Vocal Fold Dynamics in a Synthetic Self-Oscillating Model: Intraglottal Aerodynamic Pressure and Energy. J. Acoust. Soc. America 150, 1332-1345. doi:10.1121/ 10.0005882
Mullen, J., Howard, D. M., and Murphy, D. T. (2007). Real-Time Dynamic Articulations in the 2-D Waveguide Mesh Vocal Tract Model. IEEE Trans. Audio Speech Lang. Process. 15, 577-585. doi:10.1109/tasl.2006.876751

Narayanan, S., and Alwan, A. (2000). Noise Source Models for Fricative Consonants. IEEE Trans. Speech Audio Process. 8, 328-344. doi:10.1109/89. 841215

Narayanan, S., Toutios, A., Ramanarayanan, V., Lammert, A., Kim, J., Lee, S., et al. (2014). Real-Time Magnetic Resonance Imaging and Electromagnetic Articulography Database for Speech Production Research (TC). J. Acoust. Soc. America 136, 1307-1311. doi:10.1121/1.4890284

Pagliarini, S., Leblois, A., and Hinaut, X. (2021). Vocal Imitation in Sensorimotor Learning Models: A Comparative Review. IEEE Trans. Cogn. Dev. Syst. 13, 326-342. doi:10.1109/tcds.2020.3041179

Pelorson, X., Hirschberg, A., van Hassel, R. R., Wijnands, A. P. J., and Auregan, Y. (1994). Theoretical and Experimental Study of Quasisteady-flow Separation within the Glottis during Phonation. Application to a Modified Two-mass Model. J. Acoust. Soc. America 96, 3416-3431. doi:10.1121/1.411449

Pelorson, X., Hofmans, G. C. J., Ranucci, M., and Bosch, R. C. M. (1997). On the Fluid Mechanics of Bilabial Plosives. Speech Commun. 22, 155-172. doi:10. 1016/s0167-6393(97)00015-0

Perrier, P., Boë, L.-J., and Sock, R. (1992). Vocal Tract Area Function Estimation from Midsagittal Dimensions with CT Scans and a Vocal Tract Cast. J. Speech Lang. Hear. Res. 35, 53-67. doi:10.1044/jshr.3501.53

Perrier, P., Payan, Y., Zandipour, M., and Perkell, J. (2003). Influences of Tongue Biomechanics on Speech Movements during the Production of Velar Stop Consonants: A Modeling Study. J. Acoust. Soc. America 114, 1582-1599. doi:10. $1121 / 1.1587737$

Pont, A., Guasch, O., Baiges, J., Codina, R., and van Hirtum, A. (2018). Computational Aeroacoustics to Identify Sound Sources in the Generation of Sibilant/s/. Int. J. Numer. Meth Biomed. Engng 35, e3153. doi:10.1002/cnm. 3153

Ramanarayanan, V., Goldstein, L., and Narayanan, S. S. (2013). Spatio-Temporal Articulatory Movement Primitives during Speech Production: Extraction, Interpretation, and Validation. J. Acoust. Soc. America 134, 1378-1394. doi:10.1121/1.4812765

Richmond, K., Hoole, P., and King, S. (2011). "Announcing the Electromagnetic Articulography (Day 1) Subset of the Mngu0 Articulatory Corpus," in Proceedings of Interspeech 2011, Florence, Italy, August 27-31, 2011, 1507-1508. doi:10.21437/interspeech.2011-316

Rubin, P., Baer, T., and Mermelstein, P. (1981). An Articulatory Synthesizer for Perceptual Research. J. Acoust. Soc. America 70, 321-328. doi:10.1121/1.386780

Saltzman, E. L., and Munhall, K. G. (1989). A Dynamical Approach to Gestural Patterning in Speech Production. Ecol. Psychol. 1, 333-382. doi:10.1207/ s15326969eco0104_2

SAMPA (2021). SAMPA - Computer Readable Phonetic Alphabet (Www Quotation from 2021-10-27). Available at: https://www.phon.ucl.ac.uk/ home/sampa/.

Sanguineti, V., Laboissière, R., and Ostry, D. J. (1998). A Dynamic Biomechanical Model for Neural Control of Speech Production. J. Acoust. Soc. America 103, 1615-1627. doi:10.1121/1.421296

Schickhofer, L., and Mihaescu, M. (2020). Analysis of the Aerodynamic Sound of Speech through Static Vocal Tract Models of Various Glottal Shapes. J. Biomech. 99, 109484. doi:10.1016/j.jbiomech.2019.109484

Schoder, S., Weitz, M., Maurerlehner, P., Hauser, A., Falk, S., Kniesburges, S., et al. (2020). Hybrid Aeroacoustic Approach for the Efficient Numerical Simulation of Human Phonation. J. Acoust. Soc. America 147, 1179-1194. doi:10.1121/10. 0000785

Serrurier, A., and Badin, P. (2008). A Three-Dimensional Articulatory Model of the Velum and Nasopharyngeal wall Based on MRI and CT Data. J. Acoust. Soc. America 123, 2335-2355. doi:10.1121/1.2875111

Serrurier, A., Badin, P., Lamalle, L., and Neuschaefer-Rube, C. (2019). Characterization of Inter-speaker Articulatory Variability: A Two-Level Multi-Speaker Modelling Approach Based on MRI Data. J. Acoust. Soc. America 145, 2149-2170. doi:10.1121/1.5096631

Sinder, D. J., Krane, M. H., and Flanagan, J. L. (1998). Synthesis of Fricative Sounds Using an Aeroacoustic Noise Generation Model. J. Acoust. Soc. America 103, 2775. doi: $10.1121 / 1.421418$ 
Sondhi, M., and Schroeter, J. (1987). A hybrid time-frequency domain articulatory speech synthesizer. IEEE Trans. Acoust. Speech Signal Process. 35(7), 955-967. doi:10.1109/TASSP.1987.1165240

Speed, M., Murphy, D. T., and Howard, D. M. (2013). Three-Dimensional Digital Waveguide Mesh Simulation of Cylindrical Vocal Tract Analogs. IEEE Trans. Audio Speech Lang. Process. 21, 449-455. doi:10.1109/TASL. 2012.2224342

Stark, J., Ericsdotter, C., Branderud, P., Sundberg, J., Lundberg, H. J., and Lander, J. (1999). "The Apex Model as a Tool in the Specification of Speaker-Specific Articulatory Behavior," in Proceedings of the 14th International Congress of Phonetic Sciences, 1-7 August 1999, San Francisco, CA, US (, 2279-2282.

Stone, M., Davis, E. P., Douglas, A. S., NessAiver, M., Gullapalli, R., Levine, W. S., et al. (2001). Modeling the Motion of the Internal Tongue from Tagged CineMRI Images. J. Acoust. Soc. America 109, 2974-2982. doi:10.1121/1.1344163

Stone, S., Marxen, M., and Birkholz, P. (2018). Construction and Evaluation of a Parametric One-Dimensional Vocal Tract Model. Ieee/acm Trans. Audio Speech Lang. Process. 26, 1381-1392. doi:10.1109/taslp.2018.2825601

Story, B. H. (2005). A Parametric Model of the Vocal Tract Area Function for Vowel and Consonant Simulation. J. Acoust. Soc. America 117, 3231-3254. doi:10.1121/1.1869752

Story, B. H., and Titze, I. R. (1998). Parameterization of Vocal Tract Area Functions by Empirical Orthogonal Modes. J. Phonetics 26, 223-260. doi:10.1006/jpho. 1998.0076

Story, B. H., and Titze, I. R. (1995). Voice Simulation with a Body-Cover Model of the Vocal Folds. J. Acoust. Soc. America 97, 1249-1260. doi:10.1121/1.412234

Story, B. H., Vorperian, H. K., Bunton, K., and Durtschi, R. B. (20182018). An Age-Dependent Vocal Tract Model for Males and Females Based on Anatomic Measurements. J. Acoust. Soc. America 143, 3079-3102. doi:10. $1121 / 1.5038264$

Tanihara, K., Yonekura, S., and Kuniyoshi, Y. (2018). "Implementation of Respiration in Articulatory Synthesis Using a Pressure-Volume Lung Model," in Proceedings of Interspeech 2018, Hyderabad, Telangana, India, 2-6 September 2018, 2504-2508. doi:10.21437/interspeech.2018-1080

Tao, C., Jiang, J. J., and Zhang, Y. (2006). Simulation of Vocal Fold Impact Pressures with a Self-Oscillating Finite-Element Model. J. Acoust. Soc. America 119, 3987-3994. doi:10.1121/1.2197798

Titze, I. R. (1989). A Four-Parameter Model of the Glottis and Vocal Fold Contact Area. Speech Commun. 8, 191-201. doi:10.1016/0167-6393(89)90001-0

Toutios, A., Ouni, S., and Laprie, Y. (2011). Estimating the Control Parameters of an Articulatory Model from Electromagnetic Articulograph Data. J. Acoust. Soc. America 129, 3245-3257. doi:10.1121/1.3569714

Traser, L., Birkholz, P., Flügge, T. V., Kamberger, R., Burdumy, M., Richter, B., et al. (2017). Relevance of the Implementation of Teeth in Three-Dimensional Vocal Tract Models. J. Speech Lang. Hear. Res. 60, 2379-2393. doi:10.1044/2017_jslhrs-16-0395

Vasudevan, A., Zappi, V., Anderson, P., and Fels, S. (2017). “A Fast Robust 1D Flow Model for a Self-Oscillating Coupled 2D FEM Vocal Fold Simulation," in Proceedings of Interspeech 2017, 20-24 August 2017, Stockholm, Sweden, 3482-3486. doi:10.21437/interspeech.2017-844
Vampola, T., Horáček, J., and Švec, J. G. (1987). Modeling the Influence of Piriform Sinuses and Valleculae on the Vocal Tract Resonances and Antiresonances. Acta Acustica United with Acustica 101(3), 594-602. doi:10.3813/AAA.918855

VocalTractLab (2021). Towards High-Quality Articulatory Speech Synthesis (Www Quotation from 2021-10-27). Available at: https://www.vocaltractlab.de.

Vogt, F., Guenther, O., Hannam, A., van den Doel, K., Lloyd, J., Vilhan, L., et al. (2005). ArtiSynth Designing a Modular 3D Articulatory Speech Synthesizer. J. Acoust. Soc. America 117, 2542. doi:10.1121/1.4788447

von Kempelen, W. (1791). Mechanismus der menschlichen Sprache nebst Beschreibung einer sprechenden Maschine and Le Méchanisme de la parole, suivi de la description d'une machine parlante. Stuttgart: Frommann-Holzboog.

VTCalcs (2021). Software: VTCalcs for Matlab (Www Quotation from 2021-1027). Available at: https://sites.bu.edu/guentherlab/software/vtcalcs-for-matlab/.

Westbury, J., Milenkovic, P., Weismer, G., and Kent, R. (1990). X-ray Microbeam Speech Production Database. J. Acoust. Soc. America 88, S56. doi:10.1121/1. 2029064

Wilhelms-Tricarico, R. (1996). A Biomechanical and Physiologically -Based Vocal Tract Model and its Control. J. Phonetics 24, 23-38. doi:10.1006/jpho.1996.0003

Wilhelms-Tricarico, R. F., and Perkell, J. S. (1997). "Biomechanical and Physiologically Based Speech Modeling," in Progress in Speech Synthesis. Editors J. P. H. van Santen, R. W. Sproat, J. P. Olive, and J. Hirschberg (New York: Springer-Verlag), 221-234. doi:10.1007/978-1-4612-1894-4_17

Wrench, A. A., and Hardcastle, W. J. (2000). "A Multichannel Articulatory Database and its Application for Automatic Speech Recognition," in Proceedings of the 5th Seminar on Speech Production: Models and Data, Kloster Seeon, Bavaria, Germany, 1-4 May 2000 (Bavaria: Kloster Seeon), 305-308.

Zappi, V., Vasudevan, A., and Fels, S. (2016). Towards Real-Time TwoDimensional Wave Propagation for Articulatory Speech Synthesis. J. Acoust. Soc. America 139, 2010. doi:10.1121/1.4949912

Zen, H., Tokuda, K., and Black, A. W. (2009). Statistical Parametric Speech Synthesis. Speech Commun. 51, 1039-1064. doi:10.1016/j.specom.2009.04.004

Conflict of Interest: The author declares that the research was conducted in the absence of any commercial or financial relationships that could be construed as a potential conflict of interest.

Publisher's Note: All claims expressed in this article are solely those of the authors and do not necessarily represent those of their affiliated organizations or those of the publisher, the editors, and the reviewers. Any product that may be evaluated in this article, or claim that may be made by its manufacturer, is not guaranteed or endorsed by the publisher.

Copyright (c) 2022 Kröger. This is an open-access article distributed under the terms of the Creative Commons Attribution License (CC BY). The use, distribution or reproduction in other forums is permitted, provided the original author(s) and the copyright owner(s) are credited and that the original publication in this journal is cited, in accordance with accepted academic practice. No use, distribution or reproduction is permitted which does not comply with these terms. 